*Doutorando em Direito Político e Econômico pela Universidade Presbiteriana Mackenzie UPM. Mestre em Direito pela Universidade Nove de Julho - UNINOVE. Especialista em Direito Constitucional e Administrativo pela Universidade Estácio de Sá. Especialista em Direito Tributário pelo Centro Universitário das Faculdades Metropolitanas Unidas - FMU.

E-mail: jeferson@joliveiraadv. com.br

**Doutor e mestre em Direito pela Pontifícia Universidade Católica de São Paulo (PUC/ SP). Professor permanente do Mestrado em Direito e da Graduação da Universidade Nove de Julho (UNINOVE). Professor Convidado da Pós Graduação lato sensu da PUC/COGEAE e da Escola Paulista da Magistratura.Email: benamarcelo@gmail.com

\section{PrincíPIOS CONSTITUCIONAIS DA ORDEM ECONÔMICA \\ ENQUANTO INSTRUMENTO DE EQUILÍBRIO ENTRE OS DIREITOS HUMANOS E O DESENVOLVIMENTO ECONÔMICO NACIONAL}

CONSTITUTIONAL PRINCIPLES OF THE ECONOMIC ORDER AS A INSTRUMENT OF BALANCE BETWEEN HUMAN RIGHTS AND NATIONAL ECONOMIC DEVELOPMENT

\section{Jeferson Sousa Oliveira* Marcelo Benacchio**}

Como citar: OLIVEIRA, Jeferson Sousa; BENACCHIO, Marcelo. Princípios constitucionais da ordem econômica enquanto instrumento de equilíbrio entre os direitos humanos e o desenvolvimento econômico nacional. Revista do Direito Público, Londrina, v. 16, n. 2, p. 50-63, ago. 2021. DOI: 10.5433/24157-108104-1.2021v16n2p. 50. ISSN: 1980-511X

Resumo: Embora ao longo dos últimos séculos o mercado tenha sido considerado o principal meio de produção de riqueza, ainda existem aqueles que acreditam que o desenvolvimento econômico está vinculado apenas ao acúmulo de capital, relegando a defesa de direitos sociais a um segundo plano. Entretanto, a conciliação de interesses econômicos e sociais guardam significativa importância para o real desenvolvimento do Estado moderno, impedindo que abusos ocorram em prol do mercado, violando o bem-estar coletivo. Objetiva-se discutir a importância da conciliação entre direitos econômicos e sociais a fim de promover o real desenvolvimento nacional. Para tanto, vale-se do método hipotético-dedutivo, a partir de análise bibliográfica. Concluise que a consecução do real desenvolvimento está diretamente relacionada à conciliação entre direitos econômicos e sociais, não se tratando, estes, de garantias excludentes. Nesse contexto, a Constituição Federal busca integrar princípios de diferentes acepções a fim de equilibrar o desenvolvimento econômico e a defesa da dignidade humana, tida como um dos fundamentos da República.

Palavras-Chave: direitos humanos, mercado, constituição, desenvolvimento.

Abstract: Although over the past centuries the market has been considered the main means of wealth production, there are still those who believe that economic development is linked only to 
the accumulation of capital, relegating the defense of social rights to the background. However, the conciliation of economic and social interests holds significant importance for the real development of the modern State, preventing abuses from occurring on behalf of the market, violating the collective welfare. This paper aims to discuss the importance of reconciling economic and social rights in order to promote real national development. To this end, the hypotheticaldeductive method is employed, based on a bibliographical analysis. We conclude that the achievement of real development is directly related to the reconciliation between economic and social rights, which are not exclusive guarantees. In this context, the Federal Constitution seeks to integrate principles of different meanings in order to balance economic development and the defense of human dignity, considered as one of the foundations of the Republic.

Keywords: Human Rights; Market; Constitution; Development. 


\section{INTRODUÇÃO}

Desde o surgimento do capitalismo e a intensificação das relações econômicas, muito se discute a respeito da aplicação dos direitos sociais em face das relações de mercado, haja vista este ter sido responsável por diversas mazelas no passado.

Mesmo com o advento dos Direitos Humanos, o mercado ainda tem sido responsável por perpetrar severas discrepâncias econômicas, violando garantias laborais e explorando de forma predatória o meio ambiente por todo o mundo.

Tal situação não torna o mercado um vilão per si, mas enseja discussões a respeito da maneira como diversos Estados têm permitido que a atividade econômica seja exercida em seu território, vez que, em muitos casos, direitos sociais são violados em prol do desenvolvimento puramente econômico.

Visando reduzir alguns dos efeitos negativos da globalização, tal como a concentração de renda e a degradação ambiental, diferentes ordenamentos jurídicos têm buscado conciliar os interesses coletivos àqueles econômicos, impondo limites à atividade desenvolvida no mercado interno com o intuito de promover o desenvolvimento nacional.

Assim, os direitos fundamentais emergem no âmbito interno dos Estados como uma expressão dos Direitos Humanos, a qual demanda certo grau de equilíbrio e efetividade, notadamente aqueles de natureza econômica e social, de modo a permitir que o fortalecimento do mercado traga benefícios à população nacional.

Nessa toada, o Brasil, em sua Constituição Federal, traz princípios econômicos e sociais, que somados, buscam auxiliar no desenvolvimento do país, assegurando a todos uma existência digna, pautada nos ditames da justiça social.

Destarte, o presente trabalho tem como objetivo discutir sobre a necessidade de conciliar os interesses econômicos e sociais, a fim de que não haja a prevalência de um sobre o outro, gerando violações aos Direitos Humanos em decorrência da busca pelo real desenvolvimento socioeconômico. Para tanto, utiliza-se o método hipotético-dedutivo, bem como, faz-se uma breve análise bibliográfica de parte da doutrina pátria.

\section{DIREITOS HUMANOS E O DESENVOLVIMENTO DO MERCADO MODERNO}

Como é sabido, os Direitos Humanos são fruto de uma longa e árdua construção valorativa que se deu ao longo dos séculos, ao custo de inúmeras injustiças, ganhando há algumas décadas, maior notoriedade e organizando-se no modelo didático-doutrinário que atualmente se encontra.

Conforme destaca Silveira e Rocasolano (2010), o que se entende por Direitos Humanos, hoje, é marcado por uma colisão de valores da humanidade, que outrora eram impostos, mas que foram se perdendo ao longo de diversos confrontos, cedendo espaço para a liberdade, igualdade e solidariedade - também chamada por alguns de fraternidade. 
Com isso, atualmente, o conceito de dignidade humana ${ }^{1}$, embora divergente entre a doutrina, tem suas bases em garantias minimamente estabelecidas no âmbito dos Direitos Humanos, estando estes indissociavelmente relacionados. Nessa linha, Boaventura de Sousa Santos (2013, p. 42) entende que "a hegemonia dos direitos humanos como linguagem de dignidade humana é hoje incontestável. No entanto, esta hegemonia convive com uma realidade perturbadora. A grande maioria da população mundial não é sujeito de direitos humanos."

Considerando que os Direitos Humanos têm por finalidade proteger a todas as pessoas, independentemente de qualquer característica individual ou de grupo que as torne singulares, temse que a não efetivação de tais garantais constitui uma violação ao próprio fundamento de sua existência. Em outras palavras, a exclusão, notadamente quando sabida, torna a própria finalidade dos Direitos Humanos um mero exercício de retórica, violando a dignidade da pessoa humana.

O mesmo pode ser dito quanto a localidades onde supostamente tais direitos são observados, mas que ainda assim, guardam discrepâncias quanto a aplicação dessas garantias a diferentes grupos, seja por razões de custeio em sua efetivação ou qualquer outra capaz de dotar os Direitos Humanos com elevado grau de abstração e baixa efetividade.

Ao longo da história humana, em especial nas últimas décadas, violações a direitos e garantias essenciais à dignidade humana puderam, e ainda podem, ser vistas no que toca ao exercício da atividade econômica, a qual construiu valores sociais pautados no acúmulo de riquezas, especialmente em países não desenvolvidos, dificultando assim, a observância e efetivação dos Direitos Humanos a nível nacional.

A mudança de valores sociais por aqueles pautados nas relações de mercado, ascendidas principalmente a partir do pensamento de Adam Smith (COMPARATO, 2014), tornou cada vez mais a sociedade moderna sujeita aos interesses econômico-financeiro do mercado e do Estado, criando uma condição na qual "o dinheiro anestesia a consciência. Em nome dele, tudo se legitima." (NALINI, 2015, p. 11)

Isso fez com que diversos direitos - inclusive aqueles que essencialmente vão além das fronteiras políticas, tais quais os de terceira dimensão (ou geração) - sofressem com a interferência do poder econômico sobre o poder político dos Estados, criando uma condição de permissibilidade para violações, em especial, nos países não desenvolvidos, de sofrem com maior severidade os impactos do capital (STIGLITZ, 2017, p. 315).

Não obstante a complexa situação vivenciada na atualidade, Fábio Konder Comparato (2010, p. 78) aponta que "o conjunto dos direitos sociais acha-se hoje, em todo o mundo, severamente abalado pela hegemonia da chamada política neoliberal, que nada mais é do que um retrocesso ao capitalismo vigorante em meados do século XIX.”

1 Segundo Fábio Konder Comparato (2010), o que se entende por dignidade humana modernamente, foi construído sucessivamente na seara religiosa, filosófica e cientifica. Destaca-se, inicialmente, a contribuição exercida pela Bíblia e a fé monoteísta, colocando os homens em condição de igualdade entre si. Posteriormente, indagações filosóficas gregas adotaram a figura do homem como centro de seus questionamentos. Por fim, sob um viés científico, a dignidade humana adveio através de Darwin e o processo evolutivo, instigando a busca de respostas por meio do estudo. Isso não impediu que a lei estabelecesse uma regra geral voltada a considerar que todos são dotados dos menos direitos. 
Quando se aponta o retrocesso vivenciado na atualidade, é possível considerar a ausência de efetivação de tais garantias, o que vulnera o ser humano, notadamente o trabalhador, à condição de insumo no ciclo produtivo do mercado moderno (COMPARATO, 2010), o que não condiz com o texto das diversas declarações de direitos firmadas no âmbito internacional, especialmente com o advento da Idade Contemporânea, as quais abarcaram uma gama de garantias espelhadas na icônica Declaração Universal dos Direitos Humanos, proclamada pela Organização das Nações Unidas em 1948 (SILVEIRA; ROCASOLANO, 2010). ${ }^{2}$

Vale destacar que embora a origem da proteção aos Direitos Humanos date de 1815, relativamente às normas constantes no Congresso de Viena, foi a partir de 1918, após a Primeira Guerra Mundial, que seus conceitos se desenvolveram (SILVEIRA; ROCASOLANO, 2010). Instrumentos normativos como a Declaração de Direitos do Bom Povo de Virgínia (1776); a Declaração de Direitos do Homem e do Cidadão (1789); e a Declaração Universal dos Direitos Humanos (1948); bem como tantos outros que surgiram após estes, tiveram significativa importância na defesa de direitos que consubstanciam um patamar mínimo à vida digna de qualquer pessoa em qualquer país.

No entanto, mais do que um problema relativo a um ou outro sistema econômico (capitalismo ou socialismo) ${ }^{3}$, os problemas de efetivação dos Direitos Humanos residem na falta de real implementação a nível interno, além de encontrar barreiras de cunho político, deparandose com restrições culturais, ou tão somente normativas, em diversos Estados, o que implica, por vezes, em sua rejeição.

Ainda que modernamente grande parte dos abusos e violações aos Direitos Humanos não sejam fruto de ordens ou decisões arbitrarias de monarcas ou imperadores, pode-se dizer que o mercado passou a ser o grande responsável por diversas mazelas perpetradas desde o advento do liberalismo até os dias de hoje em prol do acúmulo de riquezas.

A globalização econômica, política e social vivenciada a partir da década de 1990 reformulou a maneira como o mundo estabelecia suas relações até então, sendo, o mercado, responsável por incitar grande parte dessas mudanças, de forma positiva e negativa.

Inegavelmente o aprimoramento tecnológico e científico são frutos dessa intensa relação de interdependência global, o que beneficiou milhões de pessoas ao redor do planeta, entretanto, novos problemas surgiram, afetando tantos quantos foram os beneficiados, o que pôde ser visto através do aumento, nas últimas décadas, da pobreza nos países não desenvolvidos (STIGLITZ, 2017).

Parte disso deriva do fracasso do modelo neoliberal em gerir de maneira eficiente o mercado, permitindo que o mesmo continue a perpetrar as discrepâncias econômicas presentes

2 Aqui vale-se da divisão metodológica dos principais momentos da evolução dos Direitos Humanos proposto por Silveira e Rocasolano (2010, p. 110-111), o qual compreende três etapas: a pré-história dos direitos humanos (marcada pela Idade Média e as primeiras declarações de direitos); a Idade Moderna (marcada pelos séculos XVI, XVII e XVIII, onde torna-se possível falar na história dos Direitos Humanos); e por fim, a Idade Contemporânea (direitos surgidos no século XIX e XX).

3 Nessa linha, Silveira e Rocasolano (2010), apontam que nem o comunismo idealizado por Marx e Engels, nem o capitalismo nos moldes da Escola de Chicago, foram capazes de assegurar o devido cumprimento dos Direitos Humanos. 
no liberalismo, mas que fundado nos ideais da globalização, propiciou certo grau de liberdade aos agentes econômicos, mudando valores humanos por aqueles próprios do mercado. “[...] Em consequência, sem que nos déssemos conta, sem mesmo chegar a tomar uma decisão a respeito, fomos resvalando da situação de ter uma economia de mercado para a de ser uma sociedade de mercado." (SANDEL, 2018, p. 16).

A globalização não reflete, no entanto, apenas a dimensão econômica do poder. Vai além, condicionando padrões de comportamento, em especial por meio da cultura - o que acentua a preeminência dos valores mercantis sobre os humanistas e implica um sério problema, já que o "bem-estar", principalmente na periferia do capitalismo, está condicionado a fatos e decisões que escapam à atuação dos Estados, expondo-os a crises externas. (SILVEIRA; ROCASOLANO, 2010, p. 87).

Essa mercantilização dos valores humanos mostrou-se prejudicial à proteção dos Direitos Humanos em todo o mundo, tornando Estados mais propensos a mitigarem garantias essenciais ao bem-estar social, e que compõem a dignidade humana, em função do exercício da atividade econômica, que, per si, não é algo ruim, mas a maneira como esta se desenvolve é que enseja questionamentos, principalmente quando resulta na exploração e no abuso do poder econômico.

Tais abusos ensejam, na maioria dos casos, a concentração do poder econômico e a baixa distribuição de renda, o que reflete no empobrecimento de milhões de pessoas, e assim, acaba por comprometer a capacidade destes em prover suas necessidades básicas, bem como, por limitar o desenvolvimento real dos Estados.

Nesse contexto, destaca-se que nas décadas mais recentes, diversos países na América Latina, pautados nas recomendações do Consenso de Washington, abriram seus mercados almejando que a globalização fosse capaz de prover o desenvolvimento nacional, no entanto, “[...] a globalização não cumpriu suas promessas, especialmente para os pobres.” (STIGLITZ, 2017, p. 72).

Ocorre que a pobreza e a ausência de alcance dos Direitos Humanos às populações menos abastadas não é uma exclusividade dos países não desenvolvidos, mas uma realidade que atinge também as principais potências econômicas mundiais.

Nos países mais ricos é demasiado comum haver pessoas imensamente desfavorecidas, carentes das oportunidades básicas de acesso a serviços de saúde, educação funcional, emprego remunerado ou segurança econômica e social. Mesmo em países muito ricos, às vezes a longevidade de grupos substanciais não é mais elevada do que em muitas economias mais pobres do chamado Terceiro Mundo (SEN, 2010, p. 29).

As organizações internacionais, por outrolado, têm buscado reafirmar os valores humanistas através do incentivo à cooperação internacional entre os Estados, no entanto, dificuldades emergem 
quando se considera a ausência de força vinculante entre os documentos de Direitos Humanos celebrados em seu âmbito, guardando baixa exigibilidade, ainda que considerados fontes do direito internacional e importantes balizadores normativos no âmbito interno de cada Estado signatário (SILVEIRA; ROCASOLANO, 2010).

A incorporação dessas garantias internacionais, mesmo que de forma indireta, enseja o que a doutrina denomina de direitos fundamentais, que, em síntese, diferenciam-se dos Direitos Humanos por estarem positivados no âmbito interno dos Estados, diversamente destes, que são positivados pela comunidade internacional (SILVEIRA; ROCASOLANO, 2010).

Destarte, a partir do que defende Amartya Sen (2010), tem-se que o crescimento econômico não deve ser entendido como um fim em si mesmo, mas uma ferramenta para o atingimento do real desenvolvimento humano através da conquista de amplas liberdades, sem que para isso haja o sacrifício da dignidade de muitos em prol de poucos, pois, conforme destaca Joseph E. Stiglitz (2017, p.76), “a essa altura, já ficou claro que a abertura dos mercados (redução das barreiras ao comércio, abertura aos fluxos de capital) por si só não 'resolverá' os problemas da pobreza, e pode até piora-los. O que é preciso é mais ajuda e um regime de comércio mais justo.”

\section{DIREITOS ECONÔMICOS E DIREITOS SOCIAIS}

A globalização, mais do que difundir interesses sociais, reestruturou as relações de poder por todo o mundo, desenvolvendo-se a partir do mercado e criando certo grau de assimetria econômica entre Estados e empresas.

Essa assimetria gerou, e ainda tem gerado, uma gama de problemas e questionamentos de ordem político-econômica, com efeitos que acabam por refletir na esfera social, notadamente em países não desenvolvidos.

Dentre os problemas passíveis de destaque, pode-se falar no agravamento das relações de dominação entre países ricos e pobres (SILVEIRA; ROCASOLANO, 2010), bem como naquelas entre empresas detentoras de considerável poder econômico e Estados carentes de recursos financeiros, tornando-os sujeitos à eventual captura de seu poder político.

Embora a relação de dependência entre Estados ricos e pobres não seja o foco do presente estudo, vale citar que essa condição decorre, por vezes, de questões atinentes ao mercado; interesses creditícios ou meramente políticos. Já a relação de dependência entre empresas e Estados encontra seu fundamento em interesses comuns, mas que podem acabar sendo sobrepostos por interesses unilaterais.

Em síntese, ocorre que muitos países não desenvolvidos optam por abrir seus mercados a investimentos estrangeiros, inclusive para a instalação e operação de empresas estrangeiras, flexibilizando parte de seu ordenamento jurídico sob a crença de torná-los mais competitivos ou com receio de inibir novos investimentos. ${ }^{4}$

4 “A certa altura, Papua-Nova Guiné aprovou uma lei que tornava ilegal processar companhias mineradoras internacionais fora do país, mesmo para fazer valer direitos legais, ambientais ou de saúde, temendo que esses processos desestimulassem os investimentos no país." (STIGLITZ, 2017, p. 313). 
Entretanto, nesse processo, não é incomum que Direitos Humanos ou garantias fundamentais sejam violados em prol do crescimento meramente econômico, ante a atribuição de uma falsa imagem de incompatibilidade entre o exercício dos direitos econômicos e os direitos sociais $^{5}$ (SANTOS, 2013), o que leva a uma negação destes em detrimento daqueles.

Nessa linha, Joseph E. Stiglitz (2017, p. 313-314) explica que "a competição entre os países em desenvolvimento para atrair investimentos pode resultar numa corrida ao fundo do poço, na medida em que as companhias buscam um lar com as leis trabalhistas e ambientais mais fracas."

Nota-se que diversos países, embora buscando defender ideais humanistas em seus ordenamentos jurídicos, acabam por lhes atribuir alto grau de abstração, carecendo, em termos práticos, de efetivação. Tal condição, vulnera a existência humana e a própria essência de dignidade à medida que cria uma relação assimétrica entre o desenvolvimento econômico e a proteção do meio ambiente e a justiça social.

Embora imponha realidades vinculadas principalmente ao plano da economia, a globalização ora em curso não inviabiliza a ética humanista. Ainda que inegáveis, os valores mercantilistas do capital econômico não podem preponderar sobre os valores humanos compartilhados pela comunidade internacional (SILVEIRA; ROCASOLANO, 2010, p. 87).

A sobreposição do desenvolvimento econômico em relação aos Direitos Humanos enseja discussões a respeito dos valores sociais hoje defendidos, haja vista, estes, em sua grande maioria, tratarem-se de valores de mercado - tal como: maior ganho de capital e a expansão da capacidade de consumo -, como significado de sucesso profissional e felicidade pessoal.

Desta forma, pautando-se em valores de mercado, não estranha haver certa resistência por parte de diversos agentes econômicos quanto à proteção do meio ambiente ou de valores humanos, o que implicaria em uma gradativa alteração da maneira como as relações de mercado têm se desenvolvido, exigindo uma maior responsabilização socioeconômica.

A defesa de interesses puramente econômicos enseja o que a doutrina denomina de homo oeconomicus, ou seja, "este retrataria a imagem do indivíduo cujas ações sempre racionais derivam exclusivamente de seus interesses econômicos dentro da sociedade." (PETTER, 2008, p. 31).

O caráter individualista dessa figura, segundo Ricardo H. Sayeg e Wagner Balera (2011), a princípio, impede que seja estabelecida qualquer relação horizontal entre homines economici, vez que os mesmos "[...] expressam pela ação econômica os seus instintos primitivos de sobrevivência e são, naturalmente, individualistas, concorrentes e massificados."

Embora essa figura seja capaz de vulnerar todo o meio social à medida em que se limita à esfera individual, Lafayette Josué Petter (2008, p. 36) traz que "o auto-interesse é importante e até crucial pelo papel que desempenha em transações econômicas normais."

5 “Ou seja, segundo o argumento que se ouve frequentemente, não se pode querer o incremento dos direitos sociais e econômicos, o direito à segurança alimentar da maioria da população ou o direito à educação, sem fatalmente ter de aceitar a violação do direito à saúde, dos direitos ambientais e dos direitos ancestrais dos povos indígenas e afrodescendentes aos seus territórios." (SANTOS, 2013, p. 94). 
Aqui vale destacar que ao defender a necessidade de maior observância aos Direitos Humanos e às garantias fundamentais, não se busca mudar o sistema capitalista, mas tão somente evidenciar que a busca pelo acúmulo de capital não justifica o sacrifício da dignidade humana.

Em outras palavras, objetiva-se, na verdade, a construção de um modelo capitalista pautado no real desenvolvimento coletivo, sem que disso resulte o sacrifício de muitos em prol de poucos, instituindo um modelo pautado no respeito à dignidade humana e na defesa do meio ambiente.

Ocorre que muitos ainda acreditam que a relativização de direitos sociais e a destruição do meio ambiente são parte do inevitável custo do progresso (SANTOS, 2013), entretanto, tal crença não reflete necessariamente a realidade dos fatos, pois adotar um modelo de mercado voltado à exploração predatória dos recursos naturais e humanos não resultará em desenvolvimento, mas em exaurimento, dando causa, a longo prazo, a conflitos sociopolíticos.

Destarte, tem-se que a defesa dos interesses coletivos, sejam eles sociais ou econômicos, está diretamente relacionado com o exercício do poder político, o qual nasce da vontade social, a partir de seus representantes. ${ }^{6}$ (SILVEIRA; ROCASOLANO, 2010)

Conforme esclarece Silveira e Rocasolano (2010, p. 47), “esse poder destina-se a guiar a comunidade até uma ordem social que considera adequada, impondo a seus integrantes o comportamento necessário para atingi-la, em cumprimento ao acordado no pacto social."

A ordem social imposta pelo poder político é capaz de reger também as relações econômicas, haja vista estas serem essencialmente relações sociais. Logo, o exercício dos direitos econômicos devem estar pautados nos interesses sociais, e não o contrário.

\section{PRINCÍPIOS CONSTITUCIONAIS DA ORDEM ECONÔMICA E DESENVOLVIMENTO NACIONAL}

O Brasil, assim como diversos outros países, adotou o capitalismo como seu sistema econômico, estando este, todavia, fundado, dentre outros, no respeito à dignidade da pessoa humana (art. $1^{\circ}$, III, CF) e nos valores sociais do trabalho (art. $1^{\circ}$, III, CF), a fim de construir uma sociedade justa (art. $3^{\circ}, \mathrm{I}, \mathrm{CF}$ ) e garantir o desenvolvimento nacional (art. $3^{\circ}, \mathrm{II}, \mathrm{CF}$ ).

Nesse contexto, a fim de tornar o mercado brasileiro mais justo do ponto de vista social, capaz de promover o real desenvolvimento do país, a Constituição Federal trouxe em seu bojo uma gama de princípios e normas voltadas à reger as relações negociais no mercado interno. Tais disposições, sob uma perspectiva doutrinária, ensejou discussões sobre a amplitude da chamada Constituição Econômica brasileira ${ }^{7}$. (TAVARES, 2011).

Como esclarece André Ramos Tavares (2011), a constituição econômica não está

\footnotetext{
6 "Nas democracias ocidentais, a participação dos cidadãos na vida política se limita atualmente ao breve exercício do direito ao voto, pois se tem a ideia de que o poder político pertence aos políticos, como se eles constituíssem uma classe diferente e superior. O poder político esquece que seu legítimo titular é o povo soberano." (SILVEIRA; ROCASOLANO, 2010, p. 46).

7 Entende-se, no presente trabalho, que a Constituição Econômica brasileira compreende apenas os dispositivos previstos na Constituição Federal.
} 
dissociada das demais parcelas da Constituição Federal - social e política, por exemplo - mas guarda apenas um viés delimitador para fins de estudo e análise, o que pode ser reforçado através de sua interpretação a partir do princípio da unidade constitucional, sem o qual, haveria isolamento normativo no contexto hermenêutico constitucional.

Ademais, a preocupação expressa na Constituição Federal com a dignidade humana pode ser vislumbrada também em sua matriz econômica, notadamente no artigo 170, o qual visa, com base nos ditames da justiça social, assegurar a todos uma existência digna. Segundo Silveira e Rocasolano (2010, p. 56), "o que a Constituição pretende, em última instância, é a inclusão social, mesmo que para isso intervenha no âmbito econômico, seja diante do interesse privado, seja em face do Estado-governo."

Assim, em síntese, a ordem econômica constitucional tem por fim ordenar a atividade exercida no mercado interno, delimitando valores socialmente relevantes a nível nacional, refletindo direitos fundamentais - estes pautados nos Direitos Humanos - com o intuito de equilibrar o desenvolvimento econômico do país e o bem-estar da população nacional, a partir do estabelecimento de diretrizes valorativas essenciais à formação das políticas regulatórias.

Entretanto, a proteção da dignidade humana em face dos abusos do poder econômico não pode ser tamanha a ponto de inviabilizar o desenvolvimento do mercado interno, vez que a livre iniciativa, mais do que um fundamento da ordem econômica (art. 170, caput, CF) e um dos fundamentos da República (art. $1^{\circ}, \mathrm{IV}, \mathrm{CF}$ ), é uma expressão do direito à liberdade (art. $5^{\circ}$, XIII e art. 170, parágrafo único, CF), demandando especial proteção. ${ }^{8}$ (PETTER, 2008).

Em outras palavras, deve-se se atentar para que não haja excesso de proteção às garantias sociais, ou a sobreposição destas em relação aos direitos econômicos e ao desenvolvimento do mercado interno, o que geraria uma super proteção capaz de desestabilizar o equilíbrio entre estes direitos, ambos de segunda dimensão (geração).

Com isso, pode-se perceber que o artigo 170 da Constituição Federal mescla princípios essencialmente econômicos com aqueles entendidos como integradores ${ }^{9}$, almejando assim reduzir as desigualdades econômicas entre os brasileiros ao mesmo tempo em que possibilita o fortalecimento do mercado interno. Dessa maneira, conforme ensina Lafayete Josué Petter (2008) os princípios da ordem econômica não devem ser observados de maneira individualizada, mas de modo integrado, para que assim seja possível o estabelecimento do real sentido do que se propõe - a realização da justiça social. ${ }^{10}$

Portanto, após esclarecer que a Constituição Federal, ao adotar o capitalismo como o

8 Esclarece Lafayete Josué Petter (2008), que a livre iniciativa se traduz no direito por todos detido de ingressar ao mercado, razão está que o define o capitalismo como o mais dinâmico e produtivo sistema econômico, características estas capazes de ensejar que alguns agentes abusem do poder de mercado por eles conquistado, resultando em violações a direitos das mais variadas naturezas.

9 Para André Ramos Tavares (2011) são princípios integradores previstos no artigo 170 da CF: a função social da propriedade; redução das desigualdades regionais e sociais; a busca do pleno emprego e o tratamento favorecido para as empresas de pequeno porte.

10 "Justiça social, inicialmente, quer significar superação das injustiças na repartição, a nível pessoal, do produto econômico. Com o passar do tempo, contudo, passa a conotar cuidados, referidos à repartição do produto econômico, não apenas inspirados em razões micro, porém macroeconômicas: as correções na injustiça da repartição deixam de ser apenas uma imposição ética, passando a consubstancias exigências de qualquer política econômica capitalista." (GRAU, 2015, p. 224). 
sistema econômico brasileiro, não desvencilhou o Estado do seu papel protetivo ao buscar conciliar os interesses sociais àqueles de mercado, torna-se pertinente destacar que tais princípios não visam combater o poder econômico em si, vez que este não pode ser classificado como algo bom ou ruim, mas seus efeitos e manifestações (SILVEIRA; ROCASOLANO, 2010), que, por vezes, são responsáveis pela ocorrência de abusos e violações às garantias fundamentais.

Assim, pautando-se nos Direitos Humanos, é possível defender uma postura mais humanista das relações de mercado, colocando o bem-estar e a dignidade humana como o fim buscado pela atividade econômica e não apenas o mero acúmulo de capital como forma de poder, mas este como um instrumento para o atingimento daquele.

No Brasil, isso não poderia ser diferente, vez que a dignidade humana, como já destacado, integra um dos fundamentos da República (art. $1^{\circ}$, III, CF), no entanto, como destaca Silveira e Rocasolano (2010), tais mudanças, a fim de humanizar a economia não interessam àqueles que almejam dela se aproveitar, eliminando eventuais obstáculos à sua atuação.

No que toca à indissociabilidade dos princípios integradores com os princípios econômicos, pode-se destacar a relação entre a propriedade privada (art. 170, II, CF) e a função social da propriedade (art. 170, III, CF).

A previsão de ambos os princípios no bojo do artigo 170 da Constituição Federal não se confunde com sua previsão no artigo $5^{\circ}$, XXII e XXIII, do mesmo diploma normativo. $\mathrm{O}$ artigo $5^{\circ}$, ao tratar da propriedade privada e sua função social, versa sob uma ótica social e geral, consubstanciando-os como direitos individuais e coletivos. Por outro lado, o artigo 170, ao tratar da propriedade privada e função social, atribui-lhes uma conotação econômica, versando sobre a propriedade privada dos meios de produção.

Sabendo que o principal efeito da economia de mercado é a constante geração de desigualdade (COMPARATO, 2014), o princípio da função social, fundado no princípio da solidariedade (fraternidade), almeja desconstruir o caráter individualista que recaiu sobre o direito de propriedade ao decorrer dos últimos séculos (TAVARES, 2011).

Importa destacar ainda que a função social não é maior ou capaz de desvirtuar o direito de propriedade, caso contrário, não seria possível falar em indenização havendo desapropriação (TAVARES, 2011). Logo, a função social limita-se a incentivar o exercício do direito de propriedade em prol do bem-estar geral, mas sem retirar o caráter individual do direito à propriedade privada, haja vista estar-se diante de um regime econômico capitalista.

Um importante papel cabe também aos princípios da redução das desigualdades regionais e sociais (art. 170, VII); busca do pleno emprego (art. 170, VIII) e tratamento favorecido para as empresas de pequeno porte constituídas sob as leis brasileiras e que tenham sua sede e administração no País (art. 170, IX).

A instituição de políticas capazes de amparar as empresas de pequeno porte nacionais em face daquelas já consolidadas internacionalmente demonstra sua essencialidade para o fortalecimento do mercado interno brasileiro, incentivando, inclusive, que mais pessoas participem das relações de mercado, tornando-o mais dinâmico e competitivo, resultando na criação de novos 
postos laborais e consequentemente na melhor distribuição de renda, reduzindo as desigualdades econômicas entre milhões de brasileiros.

Em outras palavras, fomentar o ingresso de novos empreendimentos e protegê-los em face dos abusos de mercado, além de se traduzir na efetivação dos direitos econômicos, permite, através da livre iniciativa art. 170, caput, CF) e da livre concorrência (art. 170, IV, CF), que o povo brasileiro busque de forma autônoma o desenvolvimento individual e contribua para o desenvolvimento social por intermédio do mercado.

Sachs (2008) entende que para garantir o emprego decente e/ou auto-emprego para todos faz necessário, dentre outras coisas, promover ações afirmativas capazes de melhorar a condição laboral daqueles que, por conta própria ou através de microempresas, busquem seu sustento, retirando-os da informalidade e incentivando sua cooperação a fim de fortalecer sua competitividade.

Cabe lembrar ainda que a empresas de pequeno porte constituem significativa parcela do mercado interno brasileiro, empregando milhares de pessoas por todo o país. Desta maneira, sua proteção faz-se essencial para a consecução dos objetivos da República, notadamente para o desenvolvimento nacional (art. $3^{\circ}, \mathrm{II}, \mathrm{CF}$ ) e para a redução das desigualdades sociais e regionais (art. $3^{\circ}$, III, CF).

O princípio da redução das desigualdades regionais e sociais exerce dupla função ao estar previsto como balizador da atividade econômica no Brasil (art. 170, VII, CF) e ao se constituir também como um dos objetivos nacionais (art. $3^{\circ}$, III, CF), pois afirma que o país está imerso a discrepâncias socioeconômicas que necessitam ser sanadas.

Dir-se-á que a Constituição, aí, nada mais postula, no seu caráter de Constituição dirigente, senão rompimento do processo de subdesenvolvimento no qual estamos imersos e, em cujo bojo, pobreza, marginalização e desigualdades, sociais e regionais, atuam em regime de causação circular acumulativa - são causas e efeitos de si próprias (GRAU, 2015, p. 215).

Muito embora o princípio da defesa do meio ambiente (art. 170, VI, CF) não seja propriamente um princípio integrador, há de considerar sua expressividade no cenário socioeconômico nacional e internacional, por se tratar de um direito de terceira dimensão (geração).

Ainda que exista muita polêmica sobre a real necessidade de proteção do meio ambiente e da instituição de medidas responsabilizatórias (DALLARI, 2004), inegavelmente a comunidade internacional, inclusive o Brasil, passou a defender os ideais do desenvolvimento econômico sustentável, pautado no equilíbrio do desenvolvimento econômico, proteção do meio ambiente e na justiça social.

Logo, falar em desenvolvimento econômico sustentável é considerar conciliar Direitos Humanos de segunda e de terceira dimensão visando assegurar a real efetivação do bem-estar social e da dignidade da pessoa humana, reafirmando, no caso do Brasil, um dos seus fundamentos.

A proteção ao consumidor (art. 170, V, CF), em meio ao sistema capitalista, demonstra 
sua importância à medida em que o gerenciamento empresarial passou a incentivar o consumo, tornando suas necessidades econômicas superiores à proteção do meio ambiente ou qualquer outro valor humano (TAVARES, 2011). Logo, busca-se, com isso, reduzir a sujeição e vulnerabilidade do consumidor em face de estratégias de marketing tidas como abusivas.

Todos esses princípios são essenciais para a consecução da soberania nacional (art. 170, I, CF), e para o atingimento dos objetivos da República (art. $3^{\circ}, \mathrm{CF}$ ), construindo um país capaz de assegurar os valores nos quais se funda, sem que para isso renegue suas garantias fundamentais a um segundo plano, conciliando os Direitos Humanos em suas diferentes acepções, especialmente a econômica e a social, viabilizando o real desenvolvimento socioeconômico do país.

\section{CONCLUSÃO}

Como pôde-se vislumbrar, embora os Direitos Humanos sejam uma construção recente na história humana, seus ideais visam assegurar uma melhor condição de vida a milhões de pessoas ao redor do mundo. No entanto, ainda que as sociedades e os mercados tenham se globalizado, o mesmo não ocorreu com os direitos.

Ainda que os Direitos Humanos tenham uma acepção de universalidade, a nível internacional, os mesmos carecem de cogência, razão pela qual são tidos apenas como balizadores normativos a nível interno.

A partir desse processo de internalização dos Direitos Humanos, tem-se o que a doutrina denomina de garantias fundamentais, as quais, têm sido relativizadas ou inobservadas por diversos países em prol do desenvolvimento puramente econômico.

Isso decorre da crença de que para haver desenvolvimento, faz-se necessário o sacrifício de barreiras normativas, que, por vezes, afetam diretamente o bem-estar e a dignidade de inúmeras pessoas.

Entretanto, não deve haver a sobreposição de interesses econômicos àqueles sociais, nem destes sobre aqueles, vez que os direitos econômicos e sociais compreendem Direitos Humanos de segunda dimensão (geração).

Assim, para que seja possível falar em um real desenvolvimento nacional, faz-se imperioso haver a conciliação de ambos os interesses (econômicos e sociais), de modo que o mercado sirva como instrumento de desenvolvimento socioeconômico.

Em outras palavras, o real desenvolvimento do Estado está condicionado ao fortalecimento do mercado e à melhoria da qualidade de vida de seus cidadãos, de modo que efetivação de garantias sociais e econômicas tornam-se o cerne da busca pelo crescimento.

Nesse contexto, a Constituição Federal brasileira, em seu artigo 170, tenta conciliar princípios econômicos e sociais integradores, a fim de permitir que o mercado interno se desenvolva de modo a auxiliar na consecução dos objetivos da República, observando ainda seus fundamentos, notadamente à dignidade humana. 


\section{REFERÊNCIAS}

COMPARATO, Fábio Konder. A afirmação histórica dos direitos humanos. 7. ed. São Paulo: Saraiva. 2010.

COMPARATO, Fábio Konder. A civilização capitalista: para compreender o mundo em que vivemos. 2. ed. São Paulo: Saraiva. 2014.

DALLARI, Dalmo de Abreu. Direitos humanos e cidadania. 2. ed. São Paulo: Moderna. 2004.

GRAU, Eros Roberto. A ordem econômica na Constituição de 1988. 17. ed. São Paulo: Malheiros, 2015.

NALINI, José Renato. Ética ambiental. 4. ed. São Paulo: Editora Revista dos Tribunais, 2015.

PETTER, Lafayete Josué. Princípios constitucionais da ordem econômica: o significado e o alcance do art. 170 da Constituição Federal. 2. ed. São Paulo: Editora Revista dos Tribunais, 2008.

SACHS, Ignacy. Desenvolvimento includente, sustentável, sustentado. Rio de Janeiro: Garamond, 2008.

SANDEL, Michael J. O que o dinheiro não compra: os limites morais do mercado. Tradução de Clóvis Marques.10. ed. Rio de Janeiro: Civilização Brasileira, 2018.

SANTOS, Boaventura de Sousa. Direitos humanos, democracia e desenvolvimento. São Paulo: Cortez. 2013.

SAYEG, Ricardo Hasson; BALERA, Wagner. O capitalismo humanista. Petrópolis: KBR, 2011.

SEN, Amartya. Desenvolvimento como liberdade. Tradução de Laura Teixeira Motta. São Paulo: Companhia das Letras, 2010.

SILVEIRA, Vladmir Oliveira da; ROCASOLANO, Maria Mendez. Direitos humanos: conceitos, significados e funções. São Paulo: Saraiva, 2010.

STIGLITZ, Joseph E. Globalização: como dar certo. Tradução de Pedro Maia Soares. São Paulo: Companhia das Letras, 2017.

TAVARES, André Ramos. Direito constitucional econômico. 3. ed. São Paulo: Método, 2011.

Como citar: OLIVEIRA, Jeferson Sousa; BENACCHIO, Marcelo. Princípios constitucionais da ordem econômica enquanto instrumento de equilíbrio entre os direitos humanos e o desenvolvimento econômico nacional. Revista do Direito Público, Londrina, v. 16, n. 2, p. 50-63, ago. 2021. DOI: 10.5433/24157-108104-1.2021v16n2p. 50. ISSN: 1980-511X

Recebido em: 15/05/2019

Aprovado em: 17/02/2020 